\title{
Editorial: Forecasting and compulsion
}

Journal of Asset Management (2007) 7, 373. doi:10.1057/palgrave.jam.2250047

Much modern research on forecasting is based around the assessment of the strength of a forecast. By segmenting the range of forecast values, it is possible to characterise the different segments by different forecast strengths. In principle, we could build trading strategies that would discourage trading when the signals are weak, and encourage increased trading when the signals are strong. The traders would probably trade much less, the riskiness of their trades would decrease, and the increased leisure time that would result could be used for personal improvement and charitable works.

However, when I have talked about these ideas with traders, I have noted reluctance on the part of my trading friends that verges on the irrational. While many modern traders are exceptionally intelligent and welleducated, they are nevertheless addicted to trading. They get an intense pleasure from their compulsive trading activity, which would be much reduced by the suggested improvements that I have mentioned in my first paragraph. Perhaps this compulsive behaviour is a good thing; without it one may never become sufficiently immersed in trading to master it. Nevertheless, it does suggest a reason why automated trading may well be the way that the industry will go in years to come.

Stephen E. Satchell Editor 